\title{
Does Clonidine Affect the Anti-Inflammatory Response of IL-10 in Patients Undergoing Laparoscopic Cholecystectomy?
}

\author{
Mohd. Faiz Ansari¹, Nitu Nigam², Neel Kamal Mishra3, Prithvi Kumar Singh4, Jitendra Kushwaha ${ }^{5}$, Radhey Shyam \\ Prem Raj Singh ${ }^{7}$, Rajni Gupta ${ }^{8}$
}

\begin{abstract}
${ }^{1} 3^{\text {rd }}$ Year Junior Resident, Department of Anaesthesiology, KGMU, Lucknow, Uttar Pradesh, India. ${ }^{2}$ Assistant Professor, Department of Centre for Advance Research, KGMU, Lucknow, Uttar Pradesh, India. ${ }^{3}$ Senior Resident, Department of Anaesthesiology, KGMU, Lucknow, Uttar Pradesh, India. ${ }^{4}$ Senior Scientific Technical Assistant, Department of Centre for Advance Research, KGMU, Lucknow, Uttar Pradesh, India. ${ }^{5}$ Associate Professor, Department of General Surgery, KGMU, Lucknow, Uttar Pradesh, India. ${ }^{6}$ Associate Professor, Department of Anaesthesiology, KGMU, Lucknow, Uttar

Pradesh, India. ${ }^{7}$ Associate Professor, Department of Anaesthesiology, KGMU, Lucknow, Uttar Pradesh, India.

8Professor, Department of Anaesthesiology, KGMU, Lucknow, Uttar Pradesh, India.
\end{abstract}

\section{ABSTRACT}

\section{BACKGROUND}

As immune mediators, cytokines are thought to regulate many biological functions. Tissue injury affects the immune system which rapidly produces pro-inflammatory and anti-inflammatory cytokines that causes injury and spread of infection to provide an appropriate environment for tissue healing. The surgery causes stressful response which leads to changes in cytokine level. Our aim was to evaluate the effects of anti-inflammatory and hemodynamic stress response of clonidine during laparoscopic cholecystectomy.

\section{METHODS}

Thirty patients [American Society of Anesthesiologists (ASA) Grade I and Grade II] were selected and randomly assigned into two groups. Group A (Normal Saline Group): Patients received $20 \mathrm{ml}$ of normal saline intravenous and Group B (Clonidine Group): patients received clonidine $1 \mu \mathrm{gm} / \mathrm{Kg}+$ normal saline $(20 \mathrm{ml})$ intravenous, 15 minutes before induction. Blood concentrations of antiinflammatory cytokines IL-10, was determined preoperatively, just after extubation and 12 hours after the operation. The cytokines assay was performed with the help of commercially available ELISA kit.

\section{RESULTS}

The demographic data age, gender, weight, height, BMI, ASA grade and baseline hemodynamic variables were comparable between group A and group B. Clonidine $(1 \mu \mathrm{gm} / \mathrm{kg}$ ) as a premedication for general anaesthesia had significantly better hemodynamic control as compared to normal saline group. IL-10 level was increased at extubation and at 12 hours postoperatively in both groups, but level was comparatively more in clonidine group as compared to normal saline group (at extubation (53.73 \pm 12.85 vs. $47.96 \pm 14.99)$ and at $12 \mathrm{hrs}$. postoperatively (110.43 \pm 13.58 vs. $96.64 \pm 44.76)$. Therefore, anti-inflammatory response IL-10 was higher in clonidine group as compared to the normal saline group.

\section{CONCLUSIONS}

Intravenous clonidine as a pre-medication could be recommended to maintain hemodynamic stability with minimal side effects during laparoscopic surgeries in ASA I/II patients. The anti-inflammatory response was greater in clonidine group as compared to saline group but not significantly different.

\section{KEY WORDS}

Clonidine, Laparoscopic Surgery, Cytokine, Interleukin-10, Anti-Inflammatory

\author{
Corresponding Author: \\ Rajni Gupta, \\ Professor, \\ Department of Anaesthesiology, \\ King George's Medical University, \\ KGMU, Lucknow, Uttar Pradesh, India. \\ E-mail: rgkgmu@gmail.com
}

DOI: $10.14260 /$ jemds/2019/659

Financial or Other Competing Interests: None.

How to Cite This Article:

Ansari MF, Nigam N, Mishra NK, et al. Does clonidine affect the anti-inflammatory response of $I L-10$ in patients undergoing laparoscopic cholecystectomy? J. Evolution Med. Dent. Sci. 2019;8(40):3032-3038, DOI: $10.14260 /$ jemds/2019/659

Submission 14-08-2019,

Peer Review 24-09-2019,

Acceptance 30-09-2019,

Published 07-10-2019. 


\section{BACKGROUND}

Laparoscopic cholecystectomy has revolutionized the area of gall bladder surgeries. It has brought great benefits over conventional surgery such as reduced tissue trauma, better cosmetic results, lesser postoperative pain and complications there by leading to early mobilization and faster recovery with shorter duration of hospital stay. Overall it is cost saving and hence, has now become gold standard for cholelithiasis surgery. As laparoscopic surgery is minimally invasive surgery, it has immune responses different from open surgery.[1,2]

Cytokines play a central role in the acute inflammatory and immune response initiated by trauma or infection. ${ }^{[3]}$ Stress response to surgery in general are reflected by cytokines and the cellular messenger system. Serum cytokines levels do not directly reflect the immune status, but demonstrate the underlying immune system activation, proving a means to recognize how laparoscopic surgery affects the metabolic and immune system. ${ }^{[4,5]}$

Antigenic products resulting from tissue injury can persuade the immune system to rapidly produce proinflammatory cytokines and other inflammatory mediators, like interleukin-1 (IL-1), interferon-gamma (Y), tumour necrosis factor (TNF), interleukin-6 (IL-6) and Creactive protein(CRP) and the anti-inflammatory cytokines such as interleukin-4, interleukin-10, prostaglandin E2, transforming growth factor-B which have local and systemic effects, which attempt to limit injury and the spread of infection, and provide an appropriate environment for tissue healing and repair. ${ }^{[3,6-8]}$ Surgical trauma represents a model of injury followed by tissue repair. The reparation process involves both neuroendocrine and immuno-inflammatory systems at the local and systemic level.[9]

Pro- and anti-inflammatory cytokines are balanced in a healthy person; however, when excessive amounts of proinflammatory cytokines are secreted during trauma, sepsis, and neoplasm, this balance is lost, resulting in increased morbidity and mortality. Thus, the suppression of harmful inflammatory responses related to surgery and anaesthesia is an important approach for improving surgical outcome.[10] For laparoscopic surgery it is required to inject gas into the abdominal cavity, creating a pneumoperitoneum, carbon dioxide (CO2) being the most used gas used for the same.[11]

The presence of $\mathrm{CO} 2$ in the abdominal cavity seems to lessen this acute phase inflammatory response, possibly causing local cellular acidosis and blocking the secretion of cytokines, altering the cytokine receptors in the liver and in other tissues or acting in hepatocytes, altering the hepatic response to inflammatory stimuli.[12] More recent studies have shown that possible mechanism whereby $\mathrm{CO} 2$ pneumoperitoneum reduces serum IL- 6 has been suggested as 1) curbing and killing bacteria and preventing the growth of Escherichia coli and Staphylococcus; 2) inducing peritoneum cell acidification, there by suppressing release of multiple inflammatory mediators and cytokines by macrophages; 3 ) inhibiting release of superoxide anion by macrophage and mitochondrial function, there by alleviating inflammatory responses.[13] So CO2 pneumoperitoneum may bring consequences to the immune response.[14]

Il-10 is an anti-inflammatory cytokine is required for regulating immune functions by promoting the widespread suppression of immune responses through its pleiotropic effects. IL-10 produced by monocytes and macrophages inhibits release of pro-inflammatory cytokines such as IL-6 and IL-8 and relieved postoperative inflammatory reaction.[15] In order to achieved successes, to limit the inflammation and hemodynamic stability, we have to know the mechanism how clonidine increases the antiinflammatory cytokines.

Clonidine, an imidazoline derivative is a selective alpha-2 adrenergic agonist, has desirable actions like anxiolysis, sedation, analgesia, antiemesis, and prevention of shivering. It is a potent antihypertensive drug. It produces a fall in heart rate and blood pressure associated with decreased SVR and cardiac output. Clonidine has a half-life of 9-12 hours suitable for anaesthesia for major surgical procedures. Clonidine inhibits the release of vasopressin and catecholamines, and modulates the hemodynamic changes induced by pneumoperitoneum, and reduces post-operative analgesic requirements,[16,17] Previously various studies reported that the reduced IL 1, IL-6, IL-8 and postoperative pain levels during and after operation, associated with preoperative epidural clonidine treatment.[18-20]

Till date there has been no study on anti-inflammatory effect of clonidine in laparoscopic surgery. Hence, present study is hypothesizing the effects of the preoperative intravenous (iv) administration of clonidine during general anaesthesia on interleukin-10 levels in laparoscopic cholecystectomy patients and also to evaluate the effects of clonidine on reduction of perioperative stress response, maintaining hemodynamic stability in laparoscopic cholecystectomy patients.

\section{METHODS}

This prospective study was performed after institutional ethical committee approval (ref. code 89th $^{\text {th }}$ ECM IIBThesis/P13). The study was conducted during the period for September, 2017 to August, 2018 in the department of Anaesthesiology, General Surgery and Surgical Gastroenterology. Total 60 patients with American Society of Anaesthesiologists (ASA) I and II patients of either sex in the age group of 20 to 60 years, undergoing laparoscopic cholecystectomy were included in this study. Sample size was calculated on the basis of alpha error of 0.05 with $80 \%$ power with 95\% confidence interval. A written informed consent form was taken from all the participant. Patients were divided into two groups ( $\mathrm{n}=30$ in each group) by using a computer-generated random number table. Group A (Normal Saline Group): Patients received $20 \mathrm{ml}$ of normal saline intravenous and Group B (Clonidine Group): patients received clonidine $1 \mu \mathrm{gm} / \mathrm{Kg}$ in $20 \mathrm{ml}$ normal saline intravenous; 15 minutes before induction.

Drug solutions were prepared by anaesthesia resident in identical syringes. The resident preparing the drug solution did not take part in patient/data management in the study. The anaesthetist managing the patient and recording data, the surgeon and the patient were unaware of group allocation of the patient. All the patients enrolled in the study undergoing laparoscopic cholecystectomy were given GA. Patients were admitted one day prior to the scheduled surgery and examined, interviewed and written consent was 
taken. There was not given hypnotic medication at evening before surgery. All patients were kept nil orally for at least 6 hours prior to starting the procedure. Upon arrival in the operating room, an 18-gauge intravenous catheter was inserted, and $6 \mathrm{ml} / \mathrm{kg} /$ hour crystalloid infusion was started. Monitors were attached and baseline parameters before premedication, e.g. heart rate, NIBP, oxygen saturation and ECG, were recorded. Particular dose of intravenous normal saline or clonidine was given $15 \mathrm{~min}$ before induction. Premedication was done and preoxygenation started. Parameters before induction were noted. Patients were induced with a standard anaesthetic protocol using fentanyl 2 $\mu \mathrm{g} / \mathrm{kg}$, propofol $2-2.5 \mathrm{mg} / \mathrm{Kg}$ and tracheal intubation will be facilitated by vecuronium bromide $0.1 \mathrm{mg} / \mathrm{Kg}$ intravenously. Anaesthesia was maintained by $\mathrm{N}_{2} \mathrm{O}: \mathrm{O}_{2}(60: 40)$ with controlled ventilation and inhalational agents (Sevoflurane) and vecuronium bromide $0.02 \mathrm{mg} / \mathrm{Kg}$ every 20-25 minutes. Nasogastric tube was placed, aspirated in all the patients to prevent gastric distension. Carbon dioxide pneumoperitoneum was established in supine position and then operation table was tilted to 10-15 degrees in reverse Trendelenburg position with left lateral tilt. Intraabdominal pressure (IAP) maintained to a pressure of 12-14 mmHg and $\mathrm{ETCO}_{2}$ was maintained between $35-45 \mathrm{~mm} \mathrm{Hg}$. Any fall in heart rate less than 60 was treated with inj. Atropine $0.6 \mathrm{mg}$ IV and rise in mean arterial pressure more than $20 \%$ from base line was treated with nitroglycerin $1-5 \mathrm{mcg} / \mathrm{kg} / \mathrm{min}$ iv with infusion. The surgical techniques were identical in all the two groups. The solution of Ringer's lactate was given to maintain the dose. Each patient received 1 gm paracetamol infused at the end of surgery intravenously Inj. Ondansetron $4 \mathrm{mg}$ iv was given prior to reverting the patient. The neuromuscular blockade was antagonized with injection of neostigmine $0.05 \mathrm{mg} / \mathrm{Kg}$ and glycopyrrolate $0.02 \mathrm{mg} / \mathrm{Kg}$ intravenously and patient was extubated, and patient shifted to post anaesthesia care unit (PACU).

Systemic arterial pressure (systolic, diastolic, and mean), heart rate, peripheral oxygen saturation $\left(\mathrm{SpO}_{2}\right)$, electrocardiography (ECG) with ST segment analysis were done at the following points at the time of surgery recorded. Venous blood $(2 \mathrm{ml})$ was collected in plain vial at preoperatively before the procedure, one at after extubation and another at 12 hours after the operation. Serum was separated by centrifugation and stored at $-20{ }^{\circ} \mathrm{C}$ for further analysis. Serum IL-10 levels were measured using human ELISA kit (Abcam, United States) according to manufactural protocol.

Statistical analysis was done using SPSS (Statistical Package for Social Sciences) Version 21.0 statistical Analysis Software. The values were represented in number (\%) and Mean \pm S.D. The data was analyzed using SPSS 16.0 statistical software. The Chi-square test and Student's t-test were used to analyze the data. The $\mathrm{p}$-value $<0.05$ was considered significant.

\section{RESULTS}

The demographic profile such as age, gender, height, weight, BMI, ASA grade and baseline hemodynamic parameters were comparable in between group A and group B as shown in
Table 1. The heart rate was comparable at the baseline $(p>0.05)$. Heart rate was found to be significantly higher among patients of group A as compared to group B at 3 min of intubation, at $10 \mathrm{~min}, 20 \mathrm{~min}, 30 \mathrm{~min}$ and $50 \mathrm{~min}$ intra-op. and at $10 \mathrm{~min} \mathrm{CO} 2$ and $10 \mathrm{~min}$ extubation [Figure 1].

Systolic blood pressure of patients of group A was found to be higher than that of group $B$ at all the periods of observation except at baseline, just before start of surgery (0 min) and at $10 \mathrm{~min} \mathrm{CO}_{2}$. Differences in systolic blood pressure of patients of Group A and Group B were found to be comparable at all the periods of observation except at 3 min intubation, at $30 \mathrm{~min}, 50 \mathrm{~min}$ and $10 \mathrm{~min} \mathrm{CO}_{2}$. At rest of the periods of observation systolic BP of patients of both the groups was comparable [Figure 2]. Diastolic blood pressure of patients of group A was found to be higher than that of group $B$ at all the periods of observation except at baseline Differences in diastolic blood pressure of patients of Group A and Group B were found to be statistically significant at all the periods of observation except at baseline, before induction, just before surgery (0 min) and at $10 \mathrm{~min} \mathrm{CO}_{2}$ [Figure 3].

Mean arterial pressure of patients of group A was found to be higher than that of group $B$ at all the periods of observation except at baseline and at $10 \mathrm{~min} \mathrm{CO}_{2}$. Differences in diastolic blood pressure of patients of Group A and Group $B$ were found to be statistically significant at all the periods of observation except at baseline, before induction, just before surgery ( $0 \mathrm{~min}$ ) and at $10 \mathrm{~min} \mathrm{CO}_{2}$ [Figure 4]. There was no significant difference in $\mathrm{SpO}_{2}$ among the groups at baseline and subsequent time intervals. Pre-operative mean interleukin levels of patients of group A (17.13 \pm 5.49$)$ was found to be higher as compared to group B $(15.58 \pm 4.26)$ but this difference was not found to be statistically significant [Table 2]. The difference in mean interleukin levels were not found to be statistically significant in between group A and group B at extubation and at 12 hrs post-operative but interleukin levels of group B were higher as compared to group $A$ at extubation $(53.73 \pm 12.85$ vs. $47.96 \pm 14.99)$ and at $12 \mathrm{hrs}$ post-operative $(110.43 \pm 13.58$ vs. $96.64 \pm 44.76)$ [Table 2].

\begin{tabular}{|c|c|c|c|}
\hline & Group A (n=30) & Group B (n=30) & p-Value \\
\hline Age (Mean \pm SD) years & $39.40 \pm 6.84$ & $39.43 \pm 6.41$ & 0.735 \\
\hline Gender & $23(76.7 \%)$ & $18(60.0 \%)$ & \\
Female & $7(23.3 \%)$ & $12(40.0 \%)$ & 0.165 \\
Male & $62.53 \pm 7.58$ & $64.97 \pm 7.27$ & 0.210 \\
\hline Weight (Mean \pm SD) Kg & $1.62 \pm 0.05$ & $1.64 \pm 0.05$ & 0.176 \\
\hline Height (Mean \pm SD) meters & $23.83 \pm 2.14$ & $24.23 \pm 2.32$ & 0.496 \\
\hline BMI (Mean \pm SD) Kg/m ${ }^{2}$ & $18(60.0 \%)$ & $15(50.0 \%)$ & \\
\hline ASA Grade & $12(40.0 \%)$ & $15(50.0 \%)$ & 0.436 \\
Grade I & $85.97 \pm 9.55$ & $85.07 \pm 10.64$ & 0.732 \\
\hline Grade II & $125.27 \pm 10.95$ & $126.60 \pm 9.95$ & 0.623 \\
\hline Heart rate & $84.87 \pm 7.48$ & $85.20 \pm 7.08$ & 0.860 \\
\hline Systolic BP & $98.33 \pm 7.08$ & $99.00 \pm 5.95$ & 0.694 \\
\hline Diastolic BP & Baseline Hemodynamic Variables \\
\hline Table 1. Demographic Characteristics of the Patients \\
\hline \multicolumn{4}{|c|}{} \\
\hline \multicolumn{3}{|c|}{ Data are represented as mean, \pm SD, n (\%) and ratio. SD=Standard deviation } \\
\hline
\end{tabular}

\begin{tabular}{|c|c|c|c|}
\hline & $\begin{array}{c}\text { Group A (n=30) } \\
\text { Mean } \pm \text { SD }\end{array}$ & $\begin{array}{c}\text { Group B (n=30) } \\
\text { Mean } \pm \text { SD }\end{array}$ & p-Value \\
\hline Pre-operative & $17.13 \pm 5.49$ & $15.58 \pm 4.26$ & 0.229 \\
\hline Extubation & $47.96 \pm 14.99$ & $53.73 \pm 12.85$ & 0.115 \\
\hline Post-operative at 12 hrs & $96.64 \pm 44.76$ & $110.43 \pm 13.58$ & 0.112 \\
\hline Table 2. Interleukin Levels of Patients at Different Time Intervals \\
\hline Data are represented as mean, \pm SD
\end{tabular}




\begin{tabular}{|c|c|c|c|c|c|c|}
\hline & \multicolumn{3}{|c|}{ Group A } & \multicolumn{3}{c|}{ Group B } \\
\cline { 2 - 7 } & $\begin{array}{c}\text { Mean } \\
\text { Change }\end{array}$ & SD & 'p' & $\begin{array}{c}\text { Mean } \\
\text { Change }\end{array}$ & SD & 'p' \\
\hline Extubation & 30.83 & 14.15 & $<0.001$ & 38.15 & 10.98 & $<0.001^{* *}$ \\
\hline Post-operative at 12 hrs & 79.51 & 47.08 & $<0.001$ & 94.85 & 12.68 & $<0.001^{* *}$ \\
\hline Table 3. Intragroup Change in Pre-Operative Interleukin Levels at \\
Different Time Intervals \\
\hline "=Significant
\end{tabular}

\begin{tabular}{|c|c|c|c|}
\hline Complications & Group A (n=30) & Group B (n=30) & p-Value \\
\hline Hypertension & $4(13.3 \%)$ & $0(0.0 \%)$ & $0.038^{*}$ \\
\hline Nausea-Vomiting & $7(23.3 \%)$ & $2(6.7 \%)$ & 0.071 \\
\hline Shivering & $5(16.7 \%)$ & $0(0.0 \%)$ & $0.020^{*}$ \\
\hline Table 4. Complications of the Patients in Between Groups \\
\hline "=Significant
\end{tabular}

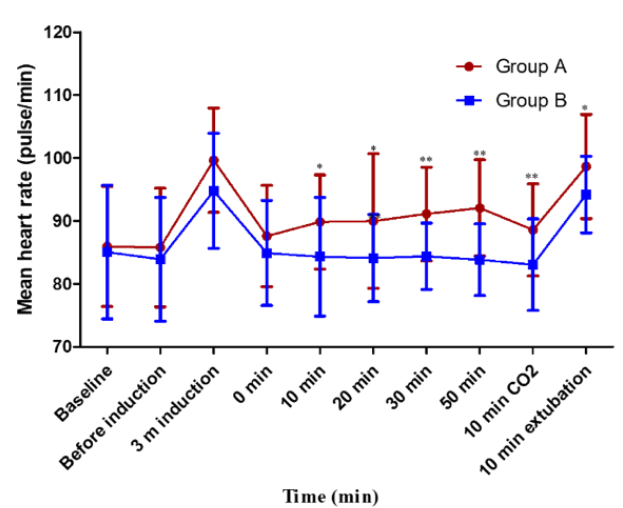

Figure 1. Heart Rate of Patients at Different Time Intervals
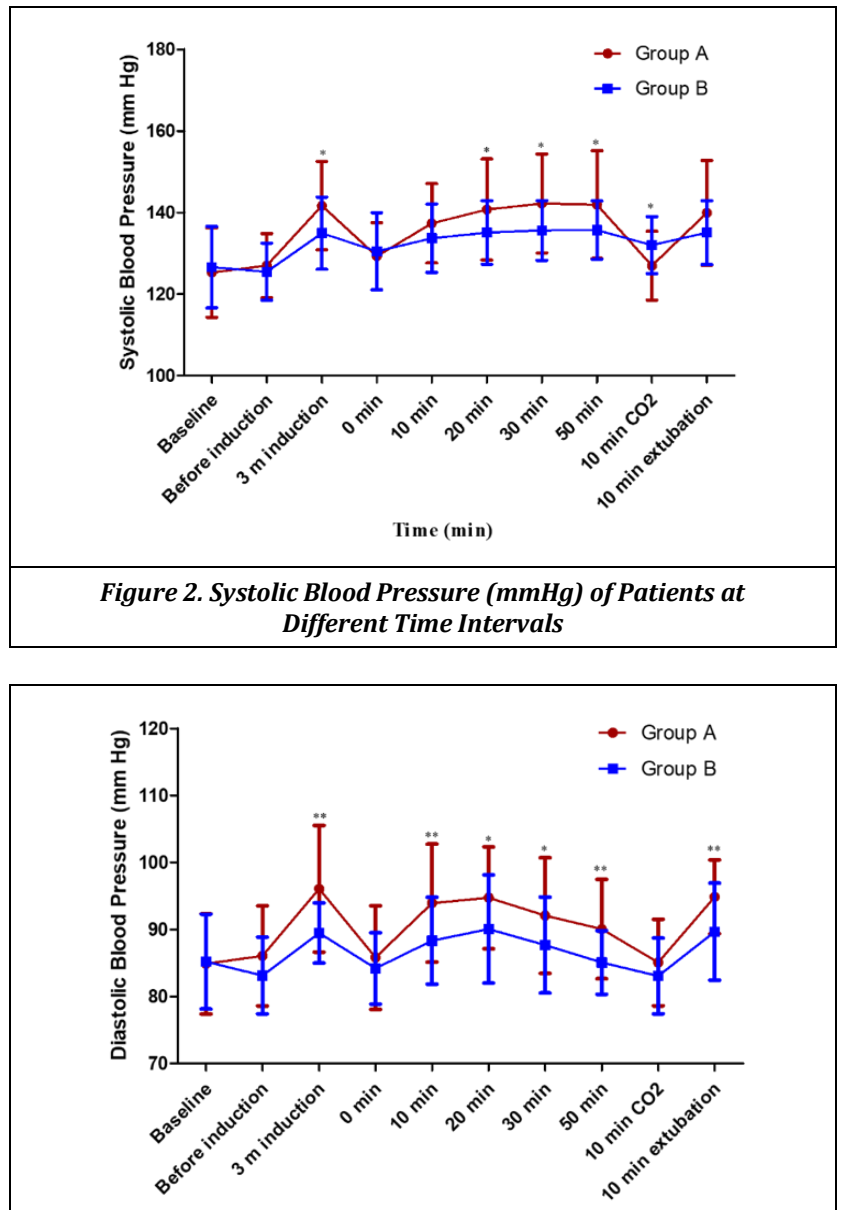

Time (min)

Figure 3. Diastolic Blood Pressure ( $\mathrm{mmHg}$ ) of Patients at Different Time Intervals

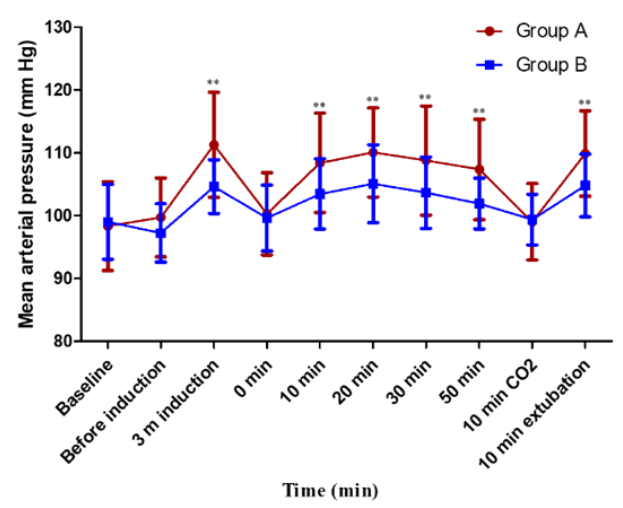

Figure 4. Mean Arterial Pressure ( $\mathrm{mmHg}$ ) of Patients at Different Time Intervals

In both groups the significant increment in pre-operative interleukin levels was observed at extubation and at $12 \mathrm{hrs}$ post-operative. In group $\mathrm{A}$ change in pre-operative interleukin levels were $180.05 \%$ and $464.32 \%$ at extubation and at $12 \mathrm{hrs}$ post-operative, while in group B was $244.81 \%$ and $608.65 \%$ [Table 3].

Nausea/vomiting were lower among the patients of group B (6.7\%) than Group A (23.3\%). Bradycardia was in 3.3\% of group B and in $60.0 \%$ of group A. Nausea/vomiting and bradycardia were statistically similar in both groups. The shivering and hypertension were present only in group A $(16.7 \%$ and $13.3 \%)$ respectively). The shivering and hypertension were statistically different in between groups [Table 3].

\section{DISCUSSION}

Laparoscopic cholecystectomy with its unique advantages is now the gold standard technique for gall bladder diseases, but the pneumoperitoneum required for this surgery has its own drawbacks. The laparoscopic cholecystectomy decreases morbidity and shortens hospital stay and return the patients to full activity early in comparison to open cholecystectomy. ${ }^{[21,22]}$ Laparoscopic surgery is always better than open because there is less inflammation and less tissue injury results in less increase in cytokines.[23] Pneumoperitoneum during laparoscopic procedure produces significant hemodynamically deviation which can be detrimental especially in old age and or patients with limited cardio-pulmonary reserve.[24] These significant changes characterized by increase in MAP, SVR, PVR and decrease in Cardiac output. Cardiac output significantly decreases as much as $50 \%$ of the preoperative value five minutes after CO2 insufflation. The paradoxical increase in RAP and PCWP after insufflations is explained by increased intrathoracic pressure.

Various practices and pharmacological agents like beta blockers, opioids, nitroglycerin, alpha-2 agonist and increasing concentration of inhalational agents, have been used to curtail these hemodynamic derangements during laparoscopy with varied results. Clonidine, a selective alpha-2 adrenergic agonist, has desirable actions like anxiolysis, sedation, analgesia, antiemesis, and prevention of shivering. It is a potent antihypertensive drug. It produces a fall in heart 
rate and blood pressure associated with decreased SVR and cardiac output.

In this study we found that the heart rate, systolic blood pressure, diastolic blood pressure, and mean arterial pressure were increased during tracheal intubation in saline group, which is continued throughout the surgery, whereas they were stable after giving clonidine. Our study is supported by $\mathrm{Yu}$ et al. (2003) who observed that clonidine stabilizes heart rate during pneumoperitoneum and recovery periods. ${ }^{[25]}$ Similarly, Tripathi et al. (2011), who reported that the hemodynamic variables were significant decreased in clonidine group as compare to saline group during intubation, pneumoperitoneum and extubation.[26] The clonidine premedication provides perioperative hemodynamic stability in laparoscopic cholecystectomy, and hence clonidine can be recommended as a routine premedication for laparoscopic procedure.[27]

In the present study, the clonidine $(1 \mathrm{mcg} / \mathrm{kg})$ as premedication for general anaesthesia had significantly better hemodynamic control than normal saline group. Our study is supported by Gupta et al. (2013) who had given clonidine $1 \mathrm{mcg} / \mathrm{Kg}$ and found that intraoperatively patient is hemodynamically stable.[28] Similarly, various studies also reported that the hemodynamic stress response was lower in clonidine group as compared to saline group. $[25,29,30]$ The attenuation of stress responses needs less use of drugs like esmolol, labetalol, propofol and nifedipine.[31,32] Clonidine thus also reduces the requirement of intraoperative analgesics and inhalational agent. Clonidine can be used as a routine premedication for laparoscopic procedure.[17]

In this study, we observed that pre-operative IL-10 level was higher in saline group as compared to clonidine group, but the difference was not significant statistically. The level of IL-10 was increased at extubation and at 12 hours postoperatively in both group but more in clonidine group, hence we found that anti-inflammatory response is higher after clonidine in post-operative laparoscopic cholecystectomy patients reflected by increased serum IL-10. Previous studies showed that plasma level of IL-10 increased after major surgery. ${ }^{[33,34,35]}$ The emergence of IL-10 as a key anti-inflammatory cytokine produced by Th2 cells is characterized by strong anti-inflammatory activity.[36] The overexpression of IL-10 can inhibit the release of proinflammatory cytokines, such as IL-6 and TNF-alpha.[13,11,12] The IL-10 not only inhibits releasing of pro inflammatory cytokines, but also limits injuries resulted from excessive inflammatory responses mediated by proinflammatory cytokines.[37] The that oral clonidine premedication increased the release of anti-inflammatory cytokines IL-10 significantly during spinal fusion surgery. [20]

Kumar et al. (2000) and Schneider et al. (2004) suggested that clonidine having role in limiting the inflammation.[38,39] The injection of the alpha -2 adrenoreceptor reduces pain behaviour and local tissue proinflammatory cytokines concentration. There ${ }^{[40]}$ is some evidence that alpha- 2 agonist affect cell mediated immune response. The activation of alpha-2 receptor by clonidine has essential role in antiinflammatory action.[41] IL-10 has been shown to inhibit the induced synthesis of IL- 6 and IL- 8 by monocytes considering these finding, our results suggest that IL-10 acts as a natural antagonist to inflammatory cytokines in a host protective manner. The effect of pharmacological doses of antihypertensive drugs on the production of IL-10, tumour necrosis factor -alpha (TNF-alpha), and IL-6 in placental tissue and peripheral blood mononuclear cells (PBMCs) from women with preeclampsia and found that clonidine can stimulates anti-inflammatory IL-10 production from placenta and PBMCs.[42] While decreasing pro-inflammatory TNFalpha, they conclude that anti-hyper tensive drugs may alter Th1/Th2 cytokine balance in pre eclamptic tissues in vitro.

However, the role of adrenoreceptors in the modulation of in vivo interleukin-10 (IL-10) production in lipopolysaccharide (LPS)-treated mice and found that the alpha-2 agonists clonidine, and xylazine significantly decrease the IL-10 plasma level, whereas the alpha-2 antagonist prazosin, increase it.[43]

In our study, the adverse effect was noted in both groups, but no any serious side effect occurred in patients of any of the groups. Higher incidence among saline group as compared to clonidine group were observed for hypertension $(13.3 \%$ vs. $0.0 \%)$, Nausea-vomiting $(23.3 \%$ vs. $6.7 \%)$ and Shivering ( $16.7 \%$ vs. $0.0 \%$ ). Differences were found to be statistically significant for incidence of Hypertension and Shivering. The incidence of postoperative nausea and vomiting was less in the clonidine group which is similar in our study.[27,44] It also reduced shivering. The clonidine inhibits cold thermo regulatory response due to an effect on central integration control and output from thermoregulatory centres.[45] Thus, he suggested that the clonidine can be used as an effective agent for inhibition of perioperative shivering which can adversely increase metabolic rate and cardiac work and may also upset surgical repair or result in wound dehiscence. However, one episode of bradycardia seen in clonidine group, but it does not require atropine.

\section{Limitations}

The sample size was fairly small in this study. Multiple observers have recorded the findings which could have a subjective bias. Surgical handling of tissue by the surgeon was also a confounding factor.

\section{CONCLUSIONS}

Clonidine is the best drug for laparoscopic surgeries. It keeps the patient hemodynamically stable with minimal side effects and increases the level of anti-inflammatory cytokine IL-10 which ultimately helps in smooth recovery and rehabilitation.

\section{REFERENCES}

[1] Alfa-Wali M, Osaghae S. Practice, training and safety of laparoscopic surgery in low and middle-income countries. World J Gastrointest Surg 2017;9(1):13-8.

[2] Yilmaz H, Arun O, Apiliogullari S, et al. Effect of laparoscopic cholecystectomy techniques on postoperative pain: a prospective randomized study. J Korean Surg Soc 2013;85(4):149-53.

[3] Zhang JM, An J. Cytokines, inflammation and pain. Int Anaesthesiol Clin 2007;45(2):27-37.

[4] Weledji EP. Cytokines and the metabolic response to surgery. J Clin Cell Immunol 2014;5:197. 
[5] Finnerty CC, Mabvuure NT, Ali A, et al. The surgically induced stress response. JPEN J Parenter Enteral Nutr 2013;37(Suppl 5):21S-9S.

[6] Feghali CA, Wright TM. Cytokines in acute and chronic inflammation. Front Biosci 1997;2:d12-26.

[7] Vittimberga FJ Jr, Foley DP, Meyers WC, et al. Laparoscopic surgery and the systemic immune response. Ann Surg 1998;227(3):326-34.

[8] Gauldie J, Richards C, Harnish D, et al. Interferon beta 2/B-cell stimulatory factor type 2 shares identity with monocyte-derived hepatocyte-stimulating factor and regulates the major acute phase protein response in liver cells. Proc Natl Acad Sci USA 1987;84(20):7251-5.

[9] Bellón JM, Manzano L, Bernardos L, et al. Cytokine levels after open and laparoscopic cholecystectomy. Eur Surg Res 1997;29(1):27-34.

[10] Gupta M, Kushwaha JK, Singh PK, et al. Opioid sparing effect of anaesthesia on postoperative inflammatory cytokine response in oral cancer surgery. J Clin Diagn Res 2018;12(1):UC10-UC15.

[11] Cheng Y, Lu J, Xiong X, et al. Gases for establishing pneumoperitoneum during laparoscopic abdominal surgery. Cochrane Database Syst Rev 2013;(1):CD009569.

[12] Silveira FP, Nicoluzzi JE, Saucedo NS Jr, et al. Evaluation of serum levels of interleukin-6 and interleukin-10 in patients undergoing laparoscopic versus conventional cholecystectomy. Rev Col Bras Cir 2012;39(1):33-40.

[13] Xufei D, Guogang Y, Shiqiong Z, et al. Laparoscopic versus open appendectomy on serum levels of cytokines in children with perforated appendices, peritonitis and sepsis. Biomedical Research 2017;28:6693-9.

[14] Wang H, Xu DF, Liu YB. Experimental study for effects of carbon dioxide pneumoperitoneum on the function of macrophage under inflammation. J Laparos Surg 2010;15:271-4.

[15] Chatterjee P, Chiasson VL, Bounds KR, et al. Regulation of the anti-inflammatory cytokines interleukin-4 and interleukin-10 during pregnancy. Front Immunol 2014;5:253.

[16] Giovannitti JA Jr, Thoms SM, Crawford JJ. Alpha-2 adrenergic receptor agonists: a review of current clinical applications. Anesth Prog 2015;62(1):31-9.

[17] Das M, Ray M, Mukherjee G. Hemodynamic changes during laparoscopic cholccystectomy: effect of clonidine premedication. Indian J Anaesth 2007;51(3):205-10.

[18] Nader ND, Ignatowski TA, Kurek CJ, et al. Clonidine suppresses plasma and cerebrospinal fluid concentrations of TNF-alpha during the perioperative period. Anesth Analg 2001;93(2):363-9.

[19] Wu CT, Jao SW, Borel CO, et al. The effect of epidural clonidine on perioperative cytokine response, postoperative pain and bowel function in patients undergoing colorectal surgery. Anesth Analg 2004;99(2):502-9.

[20] Kim MH, Hahn TH. The effect of clonidine pretreatment on the perioperative proinflammatory cytokines, cortisol, and ACTH responses in patients undergoing total abdominal hysterectomy. Anesth Analg 2000;90(6):1441-4.

[21] Joris JL, Chiche JD, Canivet JL, et al. Hemodynamic changes induced by laparoscopy and their endocrine correlates: effects of clonidine. J Am Coll Cardiol 1998;32(5):1389-96.

[22] Tripathi DC, Shah KS, Dubey SR, et al. Hemodynamic stress response during laparoscopic cholecystectomy: Effect of two different doses of intravenous clonidine premedication. J Anaesthesiol Clin Pharmacol 2011;27(4):475-80.

[23] Carlei F, Schietroma M, Cianca G, et al. Effects of laparoscopic and conventional (open) cholecystectomy on human leukocyte antigen-DR expression in peripheral blood monocytes: correlations with immunologic status. Word J Surg 1999;23(1):18-22.

[24] Xu B, Makris A, Thornton C, et al. Antihypertensive drugs clonidine, diazoxide, hydralazine and furosemide regulate the production of cytokines by placentas and peripheral blood mononuclear cells in normal pregnancy. J Hypertens 2006;24(5):915-22.

[25] Yu HP, Hseu SS, Yien HW, et al. Oral clonidine premedication preserves heart rate variability for patients undergoing larparoscopic cholecystectomy. Acta Anaesthesiol Scand 2003;47(2):185-90.

[26] Chandrashekaraiah M, Upadya DM, Jayachandran S, et al. Effects of clonidine premedication on hemodynamic changes during laparoscopic cholecystectomy - a randomized control study. Applied Cardiopulmonary Pathophysiology 2011;15(3):91-8.

[27] Medeiros AC, Araújo-Filho I, Carvalho MDF, et al. Laparoscopic versus open cholecystectomy: complications and cost. J Surg Cl Res 2012:3(2):49-58.

[28] Bhandari D, Tidke S, Sharma V, et al. Hemodynamic changes associated with laparoscopic cholecystectomy: effect of oral clonidine premedication. IOSR Journal of Pharmacy (IOSRPHR) 2012;2(4):72-7.

[29] Kulkarni K, Goel R, Talakanti SK. Effect of intravenous clonidine as premedication on haemodynamic responses during laparoscopic cholecystectomy. J Anesth Crit Care 2016;4(1):00121.

[30] Hofer S, Steppan J, Wagner T, et al. Central sympatholytics prolong survival in experimental sepsis. Crit Care 2009;13(1):R11.

[31] Ubale P, Hemantkumar I. Effect of intravenous clonidine on hemodynamic changes in laparoscopic cholecystectomy: a randomized control study. Anaesth Pain \& Intensive Care 2016;20:182-6.

[32] Sung CS, Lin SH, Chan KH, et al. Effect of oral clonidine premedication on perioperative hemodynamic response and postoperative analgesic requirement for patients undergoing laparoscopic cholecystectomy. Acta Anaesthesiol Sin 2000;38(1):23-9.

[33] Weis F, Beiras-Fernandez A, Schelling G, et al. Stress doses of hydrocortisone in high-risk patients undergoing cardiac surgery: effects on interleukin-6 to interleukin10 ratio and early outcome. Crit Care Med 2009;37(5):1685-90.

[34] Simsek E, Karapinar K, Bugra 0, et al. Effects of albumin and synthetic polypeptide-coated oxygenators on IL-1, IL-2, IL-6, and IL-10 in open heart surgery. Asian J Surg 2014;37(2):93-9.

[35] Mosser DM, Zhang X. Interleukin-10: new perspectives on an old cytokine. Immunol Rev 2008;226(1):205-18. 
[36] Sun X, Wang D, Yu H, et al. Serial cytokine levels during wound healing in rabbit maxillary sinus mucosa. Acta Otolaryngol 2010;130(5):607-13.

[37] Kato M, Honda I, Suzuki H, et al. Interleukin-10 production during and after upper abdominal surgery. J Clin Anesth 1998;10(3):184-8.

[38] Szelényi J, Kiss JP, Puskás E, et al. Opposite role of alpha2- and beta-adrenoceptors in the modulation of interleukin-10 production in endotoxaemic mice. NeuroReport 2000;11(16):3565-8.

[39] Kumar A, Creery WD. The therapeutic potential of interleukin 10 in infection and inflammation. Arch Immunol Ther Exp (Warsz) 2000;48(6):529-38.

[40] Goel S, Sinha M. Effect of oral clonidine premedication in patients undergoing laparoscopic surgery. BMJ 2006;333:519.

[41] Liang Q. Review of research on immunotherapy of severe surgical infection. Infection International 2016;5(1):1115.
[42] Schneider CP, Schwacha MG, Chaudry IH. The role of interleukin-10 in the regulation of the systemic inflammatory response following trauma-hemorrhage. Biochim Biophys Acta 2004;1689(1):22-32.

[43] Helmy SA, Wahby MA, El-Nawaway M. The effect of anaesthesia and surgery on plasma cytokine production. Anaesthesia 1999;54(8):733-8.

[44] Gvalani SK, Pawar HS. Effect of intravenous clonidine premedication in patients undergoing laparoscopic cholecystectomy. Int J Res Med Sci 2016;4:3806-11.

[45] Nicolaou G, Chen AA, Johnston CE, et al. Clonidine decreases vasoconstriction and shivering threshold without affecting the sweating threshold. Can J Anaesth 1997;44(6):636-42. 